\title{
Influence of sheet/purlin fasteners spacing on shear flexibility of the diaphragm
}

\author{
Natalia Korcz-Konkol ${ }^{1, *}$, and Elżbieta Urbańska-Galewska ${ }^{1}$ \\ ${ }^{1}$ Gdańsk University of Technology, Faculty of Civil and Environmental Engineering, \\ Narutowicza 11/12, 80-233 Gdańsk, Poland
}

\begin{abstract}
The paper presents the influence of sheet/purlin fasteners location (in reference to trapezoidal profile cross section) on shear flexibility of the cladding acting as a diaphragm. Analytical procedures were presented and their limitations were discussed. Next, selected schemes of fasteners location, known from engineering practice, but not included in European codes and recommendations, were analysed numerically in order to observe the differences in shear stiffness of the panel. The cantilevered diaphragm as a part of the roof of a single storey building was chosen for the analysis. The analysis was carried out for the valley-fixed trapezoidal sheeting with wide pans. Corrugated sheets were built by two types of models: full 3D shell model and equivalent orthotropic 2D shell model. Flexibility of fasteners and connections was included in the calculations using equivalent beam finite elements. The results were discussed from the stressed-skin design point of view.
\end{abstract}

\section{Introduction}

Trapezoidal cladding of the steel building as a part of the diaphragm affect the stiffness and spatial character of work of the structure and, by extension, deflections and crosssectional forces of particular structural members. Although the idea of the stressed skin design (the diaphragm design) has been widely known for many years [1], it is still rarely included in engineering practise. Simultaneously the development of numerical tools which support engineers in structural analysis brings new possibilities to take into consideration the stressed-skin effect. More and more effective, verified and simple to apply methods of including the diaphragm effect in structural calculations are still being searched and developed. Moreover, new technological and constructional solutions are the topics of current research studies. [2-7]

The aim of the analysis presented in the paper is to evaluate the influence of the sheet/purlin fasteners spacing (in reference to trapezoidal profile cross section) on shear flexibility of the roof cladding acting as a diaphragm. Selected schemes of fasteners location, known from engineering practice, but not included in European codes and recommendations [1,8], are analysed numerically using computer program called Autodesk Robot Structural Analysis Professional 2015 (ARSA).

\footnotetext{
*Corresponding author: natalia.korcz@pg.edu.p1
} 


\section{Model of the structure - general description}

A cantilevered diaphragm built of cold-formed members was taken into consideration, as in [6]. Main axial dimensions were 6,0 x 6,0 m, purlin spacing - 1,5 m (Fig. 1). The analysed structure included two top chords of the trusses (hat cross section profile with dimensions $114 \times 121 \times 6 \mathrm{~mm}$ ), five Z-purlins (dimensions $250 \times 60 \times 2 \mathrm{~mm}$ ) and trapezoidal cladding of the height $h=45 \mathrm{~mm}$ and two thickness variants $t(0,6 \mathrm{~mm}$ or $0,7 \mathrm{~mm}$ ). Trapezoidal sheeting with wide pans, fixed to the purlins in wider part of profile was analysed. The valley-fixed cladding was considered as it is recommended in the stressed-skin design. Geometry of the trapezoidal sheeting is presented in Fig. 2.

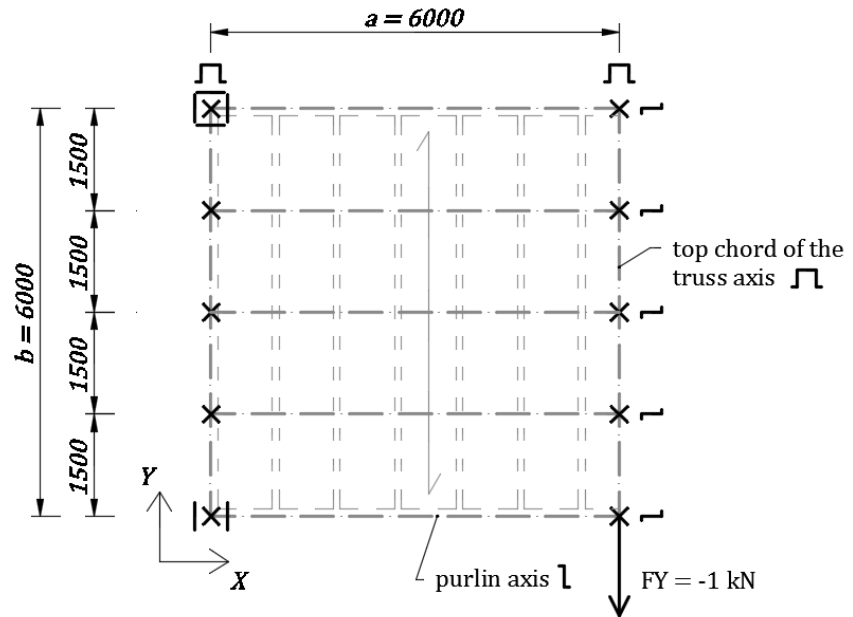

$$
\begin{aligned}
& \text { Supports: } \\
& \times \quad \text { UZ fixed } \\
& |X| \text { UZ and UX fixed } \\
& |\underline{X}| \text { UZ, UY and UX fixed } \\
& \downarrow \text { direction of sheeting } \\
& \vdash \quad \text { spanning } \\
& \neg \quad \text { one trapezoidal sheet }
\end{aligned}
$$

Fig. 1. Static scheme of the diaphragm used in the analyses [mm].

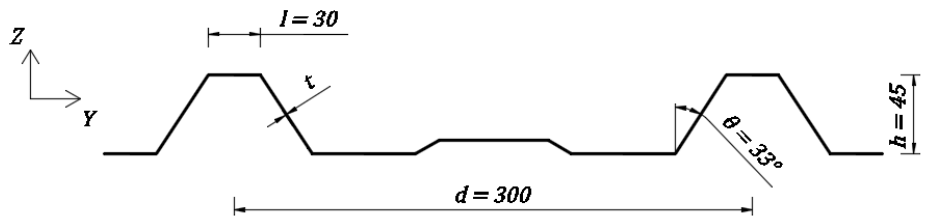

Fig. 2. Trapezoidal sheeting geometry $[\mathrm{mm}]$.

Fasteners are important components of the diaphragm. Sheet/purlin fasteners and purlin/rafter connections were taken into account in the analysis. Seam fasteners were neglected. The case of two sides fastening of the sheeting (instead of four sides fastening) was analysed, as the one of a frequent practical occurrence.

Shear load (force with the value of $1 \mathrm{kN}$ ) was axial-pointed to the top chord of the truss, as shown in Fig. 1. The supports ensured the cantilevered work of the panel. Moreover, in the points where diagonals join the top chord in the truss girder, vertical displacements were fixed (it was detected that spring supports were not necessary in this particular case).

\section{Analytical procedures}

The stressed skin design procedures accompanied by practical instructions were provided as recommendations by European Convention for Constructional Steelwork in 1995 [1]. The current version of Eurocode 3 also refers to [1] and discusses diaphragm effect very briefly [8]. 
An analytical procedure of calculating shear flexibility $c$ of the diaphragm presented in [1] is a component method: flexibility $c$ is the sum of components due to sheet deformation, fasteners and connections deformation and flange forces in the edge members (Table 1). The procedures distinguish two schemes of sheet/purlin fasteners spacing, depending on the location of fasteners in cross-section of trapezoidal sheeting: fastening in every trough $(1 \mathrm{~F})$ and fastening in alternate troughs $(2 \mathrm{~F})$, as shown in Fig. 5e-f. The values of particular components of shear flexibility of the diaphragm, calculated for two variants of the thickness $t(0,6 \mathrm{~mm}$ and $0,7 \mathrm{~mm})$ and for two cases of fastening (1F) and (2F) are presented in Table 1 .

Table 1. Components of shear flexibility of the diaphragm calculated analytically according to [1].

\begin{tabular}{|c|c|c|c|c|c|}
\hline \multirow{3}{*}{\multicolumn{2}{|c|}{$\begin{array}{c}\text { Components of shear flexibility } \\
\text { - due to: }\end{array}$}} & \multicolumn{4}{|c|}{ Values of shear flexibility [mm/kN] } \\
\hline & & \multicolumn{2}{|c|}{$t=0,6 \mathrm{~mm}$} & \multicolumn{2}{|c|}{$t=0,7 \mathrm{~mm}$} \\
\hline & & $1 F$ & $2 F$ & $1 F$ & $2 \mathbf{F}$ \\
\hline$c_{1.1}$ & profile distortion & 0,1491 & 0,7516 & 0,1014 & 0,5112 \\
\hline$c_{1.2}$ & shear strain in the sheet & \multicolumn{2}{|c|}{0,0268} & \multicolumn{2}{|c|}{0,0230} \\
\hline$c_{2.1}$ & slip in the sheet/purlin fasteners & 0,0350 & 0,0700 & 0,0350 & 0,0700 \\
\hline$c 2.2$ & slip in the seam fasteners & 0,0000 & 0,0000 & 0,0000 & 0,0000 \\
\hline$c_{2.3}$ & purlin/rafter connections & 1,1800 & 1,1800 & 1,1800 & 1,1800 \\
\hline \multicolumn{2}{|r|}{$c^{\prime}=c_{1.1}+c_{1.2}+c_{2.1}+c_{2.2}+c_{2.3}$} & 1,391 & 2,028 & 1,339 & 1,784 \\
\hline$c_{3}$ & axial strain in purlins & \multicolumn{4}{|c|}{0,023} \\
\hline & $\boldsymbol{c}=c^{\prime}+c_{3}$ & 1,414 & 2,052 & 1,363 & $\mathbf{1 , 8 0 8}$ \\
\hline
\end{tabular}

The results of shear flexibility of the analysed diaphragm (Table 1) showed that the difference between fastening in every corrugation $(1 \mathrm{~F})$ and in alternate corrugations (2F) results most from $c_{1,1}$ component (formula 1), so the component due to profile distortion. This component depends, among other things, on sheeting constant $K$ : $K_{1}$ in the case $(1 \mathrm{~F})$ and $K_{2}$ in the case $(2 \mathrm{~F})$. Moreover, constant $K$ depends on geometry of the sheeting profile - on the dimension ratios $l / d, h / d$ and on web angle $\theta$ (Fig. 2).

What is more, the choice between fastening scheme $(1 \mathrm{~F} / 2 \mathrm{~F})$ acts upon the flexibility components due to fasteners and connection deflection. Firstly, fastening every alternate troughs $(2 \mathrm{~F})$ doubles - in comparison to $(1 \mathrm{~F})$ fastening - $c_{2,1}$ component (formula 2), so the component due to sheet/purlin fasteners. In addition, the choice between $(1 \mathrm{~F} / 2 \mathrm{~F})$ fastening influences - to much lesser degree - the value of $c_{2,2}$ component (formula 3 ), so the one due to seam fasteners (omitted in these analyses) and the value of $c_{2,3}$ component (formula 4) due to purlin/rafter connection (in the analysed example this influence is not revealed).

$$
\begin{gathered}
c_{1,1}=\frac{a \cdot d^{2,5} \cdot \alpha_{1} \cdot \alpha_{4} \cdot K}{E \cdot t^{2,5} \cdot b^{2}} \\
c_{2,1}=\frac{2 \cdot a \cdot s_{p} \cdot p}{b^{2}} \\
c_{2,2}=\frac{2 \cdot s_{s} \cdot s_{p} \cdot\left(n_{s h}-1\right)}{2 \cdot n_{s} \cdot s_{p}+\beta_{1} \cdot n_{p} \cdot s_{s}}
\end{gathered}
$$




$$
c_{2,3}=\frac{2}{n_{p}} \cdot\left(s_{p r}+\frac{s_{p}}{\beta_{2}}\right)
$$

where:

$a, b \quad$ diaphragm dimensions (Fig. 1),

$d, t \quad$ trapezoidal sheeting geometry (Fig. 2),

$K \quad$ sheeting constant (explanation in the text),

$p \quad$ pitch of sheet/purlin fasteners ( $d$ in case $1 \mathrm{~F}$ and $2 d$ in case $2 \mathrm{~F}$ ),

E Modulus of elasticity,

$\alpha_{1}-\alpha_{3}$ factors to allow for the effect of intermediate purlins,

$\alpha_{4} \quad$ factors to allow for the number of sheets and fastener position (e.g. $1 \mathrm{~F} / 2 \mathrm{~F}$ ),

$\beta_{1}, \beta_{2} \quad$ factors to allow for the number of sheet/purlin fasteners per sheet width;

$n_{\text {sh }} \quad$ number of sheets per the dimension $a$,

$n_{\mathrm{s}} \quad$ number of seam fasteners per side lap (excluding those which pass through both sheets and the supporting purlin),

$n_{\mathrm{p}} \quad$ number of purlins,

$s_{\mathrm{p}} \quad$ slip per sheet/purlin fastener per unit load $[\mathrm{mm} / \mathrm{kN}]$,

$s_{\mathrm{s}} \quad$ slip per seam fastener per unit load $[\mathrm{mm} / \mathrm{kN}]$,

$s_{\mathrm{pr}} \quad$ deflection of top of purlin at purlin/rafter connection per unit load $[\mathrm{mm} / \mathrm{kN}]$.

Note: parameters to allow for the number and location of purlin/rafter fasteners are underlined.

Fastening in the centre line of valley corrugation is assumed in both cases of sheet/purlin fastening (1F/2F) according to [1]. In the case of trapezoidal sheeting with wide pans, fasteners are usually located close to webs of sheeting due to low plate stiffness of the valley corrugations (Fig. 5.1a-d). As a result the rotational spring stiffness of the purlin $C_{\mathrm{D}}$ and resistance for bending of the purlin stabilised by the cladding increase [9]. In the article the effect of lateral stabilisation of the purlin by sheeting was not considered. Instead, the influence of purlin/rafter fasteners location (close to the web of the sheeting) on shear flexibility of the panel was analysed, which can be important in the stressed-skin design.

\section{Numerical model}

Axonometric view of the numerical model of the analysed diaphragm is presented in Fig. 4. Top chords of the truss girders and purlins were applied as 3D beam finite elements with real cross sections, corrugated sheets - as shell elements (section 4.1). Fasteners and connections were substituted by equivalent beam finite elements (section 4.2).

a)

b)
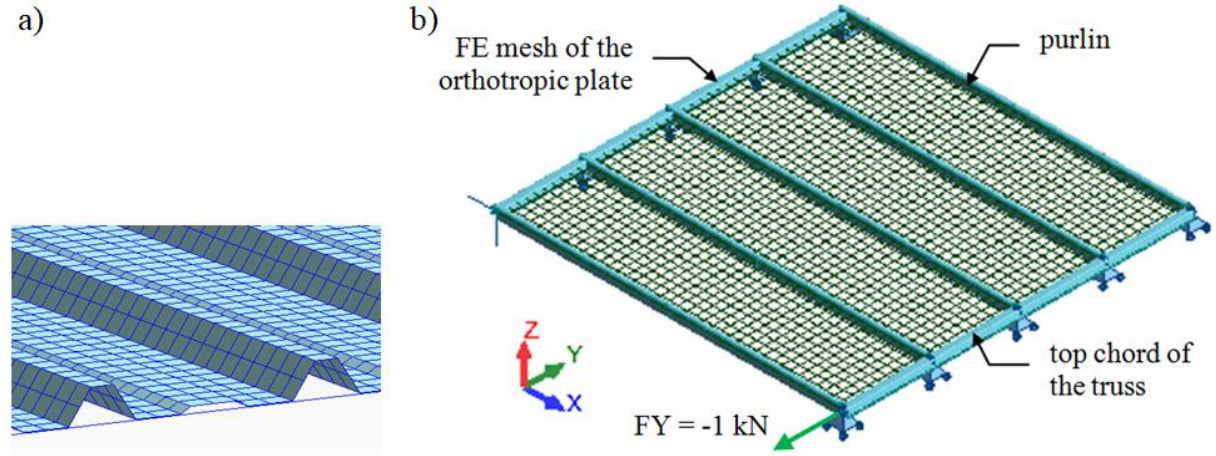

Fig. 4. Diaphragm used in the analyses - axonometric view in ARSA: a) part of fully 3D-modelled trapezoidal sheeting, b) whole structure with orthotropic 2D shell model of trapezoidal sheeting. 


\subsection{Models of trapezoidal sheeting}

Corrugated sheeting was applied in the numerical model using shell elements. Two types of trapezoidal sheeting models were built:

- fully 3D-modelled trapezoidal sheeting - „3D” (Fig. 4a),

- equivalent orthotropic 2D shell model - „Orto”.

Substitution trapezoidal sheeting by the equivalent orthotropic shell model is schematically presented in Fig. 5. The idea of this process is to find the equivalent stiffness matrix of the orthotropic 2D shell which reflects different stiffness of steel trapezoidal sheeting in perpendicular directions.
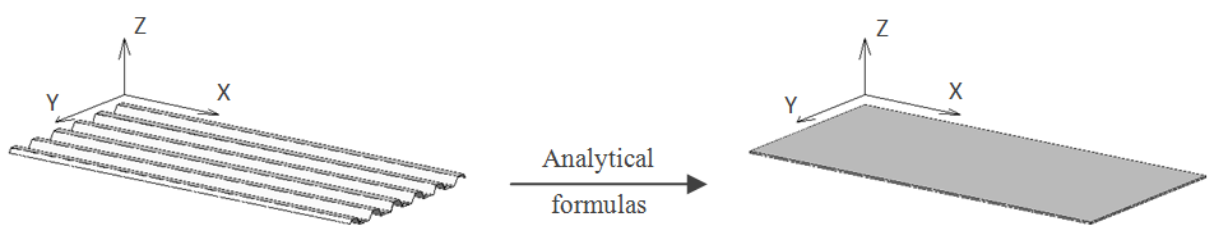

Fig. 5. The idea of substitution the fully 3D-modelled trapezoidal sheeting by the orthotropic 2D shell model [7], based on [10].

The computational programs for numerical 3D structural analysis, e.g. ARSA and RFEM, implement the tools (predefined orthotropic shells/plates) allowing the user to select the trapezoidal plate geometry instead of define stiffness matrix values of equivalent orthotropic shell. The matrix values are calculated by the program and the user is not obliged to calculate them himself. This tool was used in "Ortho" models of the shear panel. However it is worth noting that the analytical procedures for the stiffness matrix of equivalent orthotropic plate for trapezoidal sheeting, both implemented in numerical programs and known from the literature, diverge considerably. This issue is widely discussed in [6,7].

In comparison to fully 3D-modelled trapezoidal sheeting "3D", applying equivalent orthotropic 2D shell model decreases computing power requirement, time of the calculations and the size of the results file, which is particularly important in case of complex numerical models. Moreover, it reduces the work consumption of the modelling. Obviously this approach is only an approximation. One of the assumptions is the symmetrical crosssection of the cladding (while in practise asymmetrical cross-sections of sheeting are more common). The local stiffness changes are not recognised. It was suspected that equivalent orthotropic 2D shell model "Ortho" is too simplified to observe the influence of the sheet/purlin fasteners spacing (in reference to trapezoidal profile cross section) on shear flexibility of the diaphragm. That is why the analysis was carried out for two types of cladding models: "Ortho" and "3D".

\subsection{Connections and fasteners in numerical model}

Fasteners and connections flexibilities are the components of shear flexibility of the diaphragm (Table 1). In order to take into consideration these flexibilities with simultaneously slight complication of numerical model of the panel and increase of the file size, the approach introduced by [2] was adopted. In this approach theoretical slip $s$ of fasteners and connections and their placement is modelled using equivalent cantilever finite beam elements. Calculations of the cross sections of equivalent finite element were performed in $[6,7]$. 


\section{Scheme of the analyses}

Trapezoidal sheeting (in two variants of the thickness $t: 0,6 \mathrm{~mm}$ and $0,7 \mathrm{~mm}$ ) was built using two types of models: full 3D model and equivalent orthotropic model (respectively: „3D” and „Ortho” in Table 2), what is explained in section 4.1 in detail. In the case of both models, 6 schemes of sheet/purlin fasteners spacing were analysed and presented in Fig. 5 . Schemes a) - d) are the examples of fastener location not included in [1], schemes e) - f) are the examples related to the procedures based on [1] (explained in section 3). While computing shear flexibility of the panel according to [1], local stiffeners of the sheet are not taken into account. That is why stiffeners were neglected also in the numerical models $(1 \mathrm{~F})$ and $(2 \mathrm{~F})$.

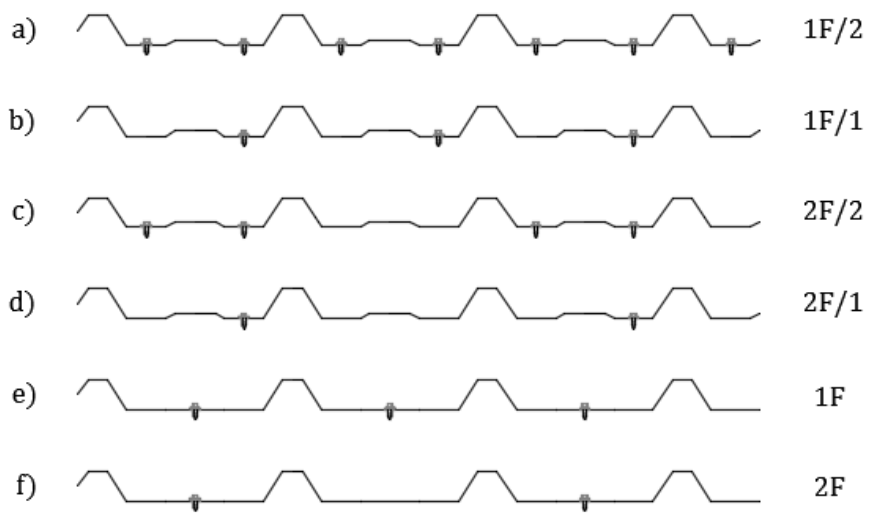

Fig. 5. Schemes of sheet/purlin fasteners spacing: a) scheme $1 F / 2$, b) scheme $1 F / 1$, c) scheme $2 F / 2$, d) scheme $2 \mathrm{~F} / 1$, e) scheme $1 \mathrm{~F}$, f) scheme $2 \mathrm{~F}$.

\section{Results and conclusions}

Values of shear flexibility of the diaphragm obtained for two types of trapezoidal sheeting model: 3D model ("3D") and orthotropic shell model ("Ortho") are presented in Table 2. The differences between "3D" and "Ortho" values (column " $\Delta$ ") and percentage values of these differences related to the "3D" values (column "\%") were calculated. The results are also shown in Fig. 6.

Table 2. Shear flexibility of the diaphragm.

\begin{tabular}{|c|c|c|c|c|c|c|c|c|}
\hline \multirow{3}{*}{$\begin{array}{c}\text { Fasteners } \\
\text { Spacing }\end{array}$} & \multicolumn{8}{|c|}{ Shear flexibility of the diaphragm $[\mathrm{mm} / \mathrm{kN}]$} \\
\hline & \multicolumn{4}{|c|}{$t=0,6 \mathrm{~mm}$} & \multicolumn{4}{|c|}{$t=0,7 \mathrm{~mm}$} \\
\hline & 3D & Ortho & $\Delta$ & $\%$ & 3D & Ortho & $\Delta$ & $\%$ \\
\hline $1 \mathrm{~F} / 2$ & 1,321 & 1,207 & 0,114 & 8,6 & 1,217 & 1,197 & 0,020 & 1,6 \\
\hline $1 \mathrm{~F} / 1$ & 1,454 & $1,454^{\text {a) }}$ & 0,000 & 0,0 & 1,374 & $1,392^{\mathrm{a})}$ & $-0,018$ & $-1,3$ \\
\hline $2 \mathrm{~F} / 2$ & 2,047 & 1,477 & 0,570 & 27,8 & 1,765 & 1,396 & 0,369 & 20,9 \\
\hline $2 \mathrm{~F} / 1$ & 2,432 & $2,225^{\mathrm{b})}$ & 0,207 & 8,5 & 2,023 & $1,920^{\mathrm{b})}$ & 0,103 & 5,1 \\
\hline $1 \mathrm{~F}$ & 1,470 & $1,454^{\mathrm{a})}$ & 0,016 & 1,1 & 1,396 & $\begin{array}{l}\left.1,392^{\mathrm{a}}\right) \\
\end{array}$ & 0,004 & $0,0,3$ \\
\hline $2 \mathrm{~F}$ & 2,230 & $2,225^{\mathrm{b})}$ & 0,005 & 0,2 & 1,941 & $1,920^{\mathrm{b})}$ & 0,021 & 1,1 \\
\hline
\end{tabular}

a) the spacing $(1 \mathrm{~F} / 1)$ and $(1 \mathrm{~F})$ are identical in case of „Ortho” models

b) the spacing $(2 \mathrm{~F} / 1)$ and $(2 \mathrm{~F})$ are identical in case of „Ortho" models 
The values of shear flexibility of the panel in the case of schemes (1F) and (2F) (Table 2) refer to analytical values calculated according to [1] (Table 1). In the case of every corrugation fastening $(1 \mathrm{~F})$, the differences between analytical and numerical values of the flexibility (related to analytical values) did not exceed $4 \%$ and in the case of fastening in alternate corrugation $(2 \mathrm{~F})$ - did not exceed $9 \%$. A proper agreement between analytical and numerical results was the starting point to analyse the schemes of fastener spacing, not included in [1].

Shear flexibility of the diaphragm $[\mathrm{mm} / \mathrm{kN}]$

(sheet thickness $t=0,6 \mathrm{~mm}$ )

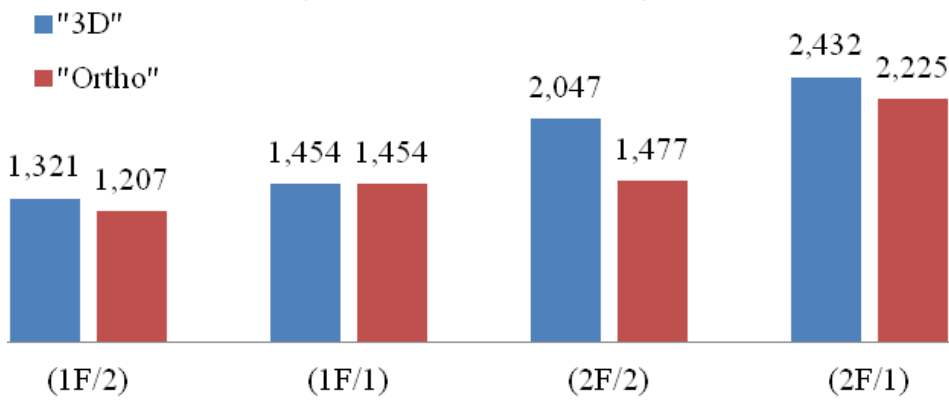

Sheet/purlin fasteners spacing

Shear flexibility of the diaphragm $[\mathrm{mm} / \mathrm{kN}]$

(sheet thickness $\mathrm{t}=0,7 \mathrm{~mm}$ )

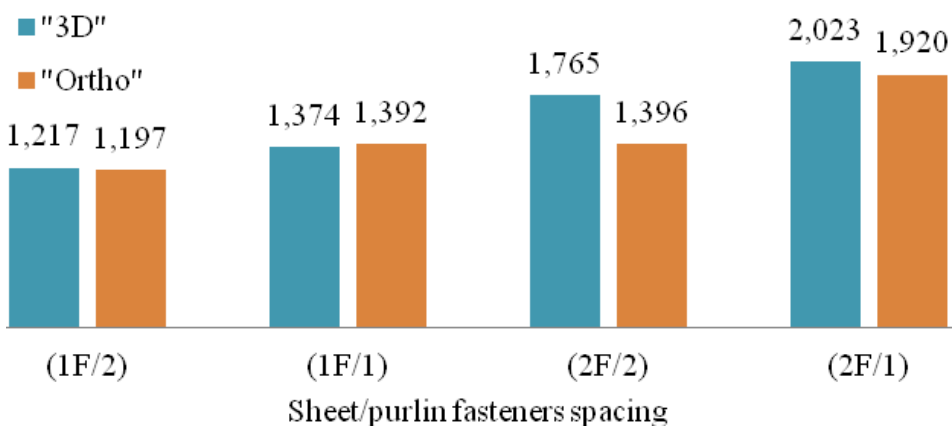

Fig. 6. Shear flexibility of the diaphragm depending on the scheme of sheet/purlin fasteners spacing for two numerical models of the sheeting: „3D” and „Ortho" (description in the text).

Small differences between values of the flexibility achieved for schemes $(1 \mathrm{~F} / 2)$ and $(1 \mathrm{~F} / 1)$ signalize that - in case of analysed structure - increasing the number of purlin/rafter fasteners (from one per corrugation to two per corrugation) from the stressed skin design point of view is not cost-effective.

The analysis showed that in the case of the analysed structure, the diaphragm in scheme $(2 \mathrm{~F} / 2)$ is more flexible than in scheme $(1 \mathrm{~F} / 1)$, while the number of sheet/purlin fasteners per the length of the purlin is the same (,3D” model: $41 \%$ increase of flexibility value was noted for the sheet thickness $t=0,6 \mathrm{~mm}$ and $28 \%$ increase for $t=0,7 \mathrm{~mm}$ ). The scheme of sheet/purlin fasteners, beneficial for the rotational spring stiffness $C_{\mathrm{D}}$ of the purlin stabilised by the cladding is disadvantageous from the stressed-skin design point of view. The increase of flexibility values were observed only for „3D" models. For “Ortho" models the influence weren't revealed (Fig. 6). Discrepancy between values obtained for both models is interpreted as the confirmation that „Ortho" model includes number of fasteners 
(component $c_{2.1}$ ) but is not sensitive to their location (particularly do not consider fasteners location in regard to webs of sheeting and their effect on the sheet deformation - $c_{1.1}$ component).

The "Ortho" models brought good results for schemes of fasteners close to assumptions based on [1], e.g. for the scheme $(1 \mathrm{~F} / 1)$. For schemes, which depart from the assumptions of [1], for example for the scheme $(2 \mathrm{~F} / 2)$, increase of discrepancies between models "Ortho" and "3D" were observed.

The effect of stabilisation of the purlin by sheeting was not considered in the article. However, it can be derived from the results that it is worth to analyse the influence of the irregularity of sheet/purlin fasteners spacing (e.g. in the scheme $(2 \mathrm{~F} / 2)$ as in [9]) on the linear stiffness of the purlin restrained by cladding.

Taking into consideration the work consumption of fully 3D-modelling of trapezoidal sheeting " $3 \mathrm{D}$ " it is obvious that this model cannot be used in engineering practise. That is why the awareness of the consequences of using equivalent numerical models (as "Ortho" model) among the engineers is so important.

\section{References}

1. European Recommendations for the Application of Metal Sheeting Acting as a Diaphragm. Stressed Skin Design. ECCS - TC7, TWG 7.5 (May 1995)

2. M. Gryniewicz, J. K. Szlendak, FEM model of the steel building roof includes stressed skin diaphragm action effects, in: M. A. Giżejowski et al. (Eds): Proceedings of The XIII ICMS "Recent Progress in Steel and Composite Structures" (CRC Press, 2016)

3. A. L. Joó, L. Dunai, Full-scale experimental tests on steel frames with various claddings, in: Proceedings of The Eighth International Conference on Advances in Steel Structures (2015)

4. A. Lendvai, A. L. Joó, Test based finite element development for diaphragm action. in: Proceedings of The International Colloquium on Stability and Ductility of Steel Structures (2016)

5. Zs. Nagy, A. Pop, I. Mois, R. Ballok, Stressed Skin Effect on the Elastic Buckling of Pitched Roof Portal Frames, Structures, 8, 227-244 (2016), http://dx.doi.org/10.1016/j.istruc.2016.05.001

6. N. Korcz, Modele numeryczne uwzględniające tarczową pracę pokrycia dachowego z blach trapezowych, JCEEA, XXXIV, 64 (4/I/17) (2017). DOI: 10.7862/rb.2017.207

7. N. Korcz, E. Urbańska-Galewska, Influence of fasteners and connections flexibility on deflections of steel building including the stressed skin effect, Technical Science, No. 21(2)2018 (2018)

8. EN 1993-1-3:2006. Eurocode 3. Part 1-3

9. M. Gajdzicki, J. Goczek, Ł. Kwiatkowski, Wpływ rozmieszczenia łączników mocujących poszycie z blachy trapezowej na sztywność obrotową podparcia sprężystego. Inżynieria i Budownictwo, 6 (2017)

10. D. Wennberg, P. Wennhage, S. Stichel, Orthotropic Models of Corrugated Sheets in Finite Element Analysis, ISRN Mechanical Engineering, 2011 (2011) DOI:10.5402/2011/979532 